\title{
Consumer's perspectives on horticultural herbal derivatives
}

\begin{abstract}
This paper identifies consumers' perspectives and inclinations on health issues regarding usage on horticultural herbs and herbal products. This study was carried in the state of Sabah, Malaysia where respondents are of different ethnics and working groups. Questionaires were distributed, which probed into consumerism factors and behaviors as well influences of the mass media. Study found out that factors such as product commercialisation, consumers preferences, media influences and job opportunites have positive impacts. Factors identified had contributed towards consumer development model for a healthier lifestyle through the consumption horticultural herbal products and its derivatives. Future planning and implementation of developmental strategies can further affect global horticultural businesses.
\end{abstract}

Keywords: horticultural herbal products, consumerism factors, behaviours, healthy lifestyle, global businesses
Volume 3 Issue 4 - 2019

\author{
Noraini Abdullah,' Suhaimi Salleh, ${ }^{2}$ \\ 'Senior Lecturer, Mathematics with Economics Program, \\ Universiti Malaysia Sabah, Malaysia \\ ${ }^{2}$ Senior Lecturer, Communication Program, Universiti Malaysia \\ Sabah, Malaysia
}

Correspondence: Noraini Abdullah, Senior Lecturer (PhD), Mathematics with Economics Program, Universiti Malaysia Sabah, Jln.UMS 88400, Kota Kinabalu, Malaysia,

Email noraini@ums.edu.my,norainiabdullah.ums@gmail.com

Received: July 10, 2019 | Published: August 08, 2019

\section{Introduction}

Plants are the essentials of life on Earth, and research in the field of enhancing the quality and quantity of agricultural production is indispensable. Horticultural research from different perspectives are needed to be studied such as from the aspect on climate change, horticultural activistes and consumers perspectives. Ethnopharmacologists play a significant role in the development of conventional medicine. Collaborations on bio-based research on plants are suggested. ${ }^{1}$ A growing global interest in herbal and alternative medicine ${ }^{2}$ in the United States was indicated where the market for herbal products had reached US\$590.9 millions. This study thus identifies the factors derived from consumers' perspectives regarding herbs and herbal products usage as alternatives or supplementaries to their everyday diet.

Usage of herbs and herbal horticultural products by the global communities had been taken for granted and some even used them without prior knowledge to their medicinal properties. Herbs like cinnamon had been used in culinary and as food additives. ${ }^{3,4}$ In Asia, cinnamon is used to treat gout, rheumatic pains, and inflammation, body revitaliation after birth and confinement, stomach aches and constipation. ${ }^{3,5}$ Cinnamon was used to control blood sugars where its extracts had not only improve insulin effectiveness but also hinders the inactive enzymes and hence, increased the breakdown of glucose, hence, can reduce the risks of contracting diabetes and stroke. ${ }^{6}$

Garlic too was known to contain active medicinal compositions, and had been used thousands of years ago in herbal medicine. ${ }^{7}$ Various animal experiments have revealed that garlic extracts lowered plasma lipid and cholesterol, and to possess antithrombotic, ${ }^{7}$ and fibrinolytic properties. Risks of contracting diseases like diabetes melitus, cardiovasculars, and cancers ${ }^{8}$ can be reduced with the intake of horticultural herbal products like garlic, ginger and turmeric ${ }^{9}$ besides treatment to reduce high blood pressure and anti-inflammation for hypertension of cardiovascular patients..$^{10}$

Ginger has become a important horticultural commodity in the South East Asian region, and is known to have many uses in different applications of traditional medicine, and extracted for its oils in modern medicine. ${ }^{3,11}$ Most countries especially China and India, use fresh ginger in their everyday food preparations, drinks like gingerflavoured tea and coffee and menus. ${ }^{12}$

Turmeric, the spice that has been used for centuries in food preparation and in traditional medicines to treat numerous diseases and conditions. The primary biologically active constituent of polyphenol, curcumin, has potent anti-inflammatory and antioxidant properties, contributing to its potential to prevent such conditions like cancer, Alzheimer disease, heart disease, and arthritis. ${ }^{13,14}$ Curcumin exhibits anti-inflammatory, antioxidant, anticancer, antiviral, and neurotrophic activity and therefore holds promise as a therapeutic agent to prevent and treat several disorders. ${ }^{15}$

\section{Materials and methods}

The data in this research were administered via questionnaires. To measure the consistency and reliability of a test subject, the Alpha Cronbach value has to be taken into account which stands within the range of zero to one $(0 \leq \alpha \leq 1)$. A value nearing to zero would show a higher degree of consistency, while a value surpassed over 0.5 indicates that the data collected are both consistent and reliable. ${ }^{16}$

Some locally grown horticultural herbs which were the product focus under study for consumer perspectives were Cinnamon (Cinnamomum iners), Garlic (Allium sativum), Ginger (Zingiber officinale), and Turmeric (Curcuma longa). Main Factors studied in promoting the use of herbal products or derivatives were on consumers' behaviour cum consumers' attitudes and preferences, influences on consumers' perception, awareness of benefits, perception of the role of media, product commercialisation and utilisation.

\section{Results}

Data collected via questionnaires to 550 respondents. The Alpha Cronbach values for the whole encompassing factors were 0.699 , $0.657,0.621$, and 0.695 for cinnamon, garlic, ginger, and turmeric respectively. Thus, it can deduced that the overall collected data were consistent and reliable. 


\section{Demographic profiles}

The demographic factors studied were age, sex, faith/religion, marial status, and level of education, area of living and income. The highest number of respondents were indigenous Sabahans (43\%), followed by Malays (39\%), Chinese (13\%), Indians (3\%), and indigenous Sarawakians ( $2 \%)$. In terms faith, on average most of the respondents were Muslims (70.4\%), followed by Christians (23\%), Buddhists and others $(6.6 \%)$. The highest formal education was at Bachelor's level. However, most of the respondents had tertiary or Diploma level qualifications, and with a household income between RM 500-RM3,000. Majority respondents resided in the urban areas $(68.9 \%)$ while the rest settled in homes located in rural areas $(31.1 \%)$.

\section{Consumers behaviour}

This study examined the factors on consumers' behaviour regarding the use of herbs and horticultural products. Aspects like the use of herbs in cooking, for health and well-being, use in beauty treatment and medication. The frequencies of usages and preferences were investigated as shown in Figure 1. Around 96.7\% use herbs, specifically garlic everyday, while $69.3 \%$ only prefer them, with $92 \%$ perceived it as a necessity, and $79.3 \%$ use herbs frequently. Herbs (cinnamon, garlic, ginger and turmeric) were considered as a kitchen necessity, particularly, their culinary uses were the main reason as compared to the other uses. Use of herbs in cooking recorded the highest percentage (98.7\%) compared to its use in medicine (24.7\%), health and well-being (18\%), and beauty (7.3\%). Eventhough the percentages of respondents on the usages were low, they knew the benefits and effects of the herbs and herbal products usages.

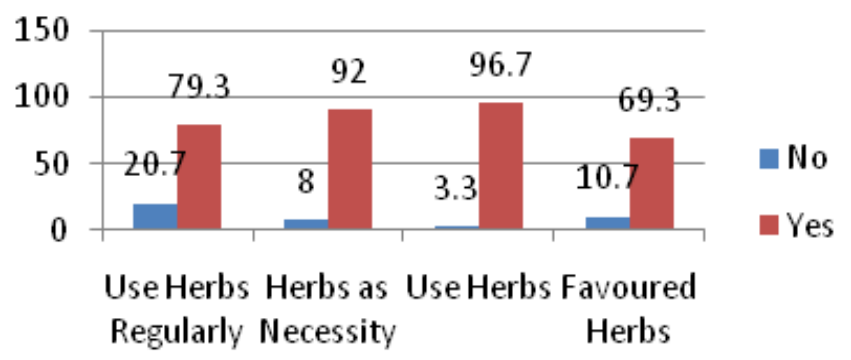

Figure I Frequencies on usage of herbs in sabah, Malaysia.

\section{Consumers' attitudes and preferences}

This factor on consumers' attitudes and preferences was studied so as to observe how consumers' preferences on using herbs and its impact in their daily lives. Questions on preferred ways of preparations in dishes and menus, and at what time or events were the herbs used, along with the consumers' attitudes towards the dishes if the herbs were not used, were all incorporated in the questionnaires. Findings indicated that since these herbs are not the leafy types, the consumers perferred these herbs to be cooked $(94 \%)$, rather than raw $(12 \%)$. Some preferred in powder form $(5.3 \%)$, capsules $(6 \%)$, and crushed $(8 \%)$. In addition, these herbs were preferred to be used at lunch time (70\%) and dinner time (77.3\%), as compared to breakfast (40.7\%) and evening tea times (40\%). Despite the high herbal usage in cooking (94\%), only $78 \%$ considered their meals as incomplete without its addition. This may be due to the preference of just using a herb like garlic in everday cooking, which is not equivalent to compulsive usage in flavouring their dishes.

\section{Influences on consumers' perception}

This factor examined the elements that influenced the way the consumers used the the herbs. The questionnaires posed questions comprised of determined influencing factors, availability of herbs and herbal products, and the conveniences of usage. The analysis of herbs obtainability whether from supermarkets, groceries, farmers' markets or even self-grown horticulteurs with regards to pricing were also taken into consideration.

Results showed that most consumers preferred the herbal usage due to its 'pleasant' flavour (72.7\%) as compared to other factors eg., convenience of usage, obtainability, affordability, and consumers' confidence. Price was not a very strong factor influencing consumers' demand since majority of them $(96.7 \%)$ stated that they were affordable. Highest percentage on herbs usage were from supermarkets, followed by groceries, farmers market and lastly, selfgrown users. The highest percentage of sources where consumers had referred to were: family traditions (54\%), mass media (40.7\%), health books (35.3\%), and finally, friends and neighbours (22.7\%).

\section{Awareness of herbal products benefits}

This factor on consumers' awareness on benefits of herbal products was examined based on the answers to the questions about use and effectiveness of herbs in alternative medicine for treating ailments. Most responses were positive, however, they were unsure in consulting a doctor prior to treatment using herbs (mean:3.17; mode: 3.0).

Consumers were found to be confident in herbal usage in treating ailments (mean:3.97; mode:4.0), while had practiced and believed in the treatments' effectiveness with a mean score of 3.26 (mode:4.0).

\section{Perception of the role of media}

Media plays a vital role in passing information across to the public. However, have the media played their role in sharing and imparting the knowledge on the benefits of a healthy lifestyle encompassing herbal usages to the society? A selection of questions require the consumers to rate the media on a likert scale of 1 to 5 .

Most respondents agreed with importance of the media and its role in conveying the beneficial uses of herbs to them (mean: 3.89; mode :4), but they disagreed with statements that the mass media frequently airs programmes of the health genre (mean : 2.45 ; mode :2), and that government-run media have played a large role in promoting herbal products (mean :3.33; mode :4). Respondents also disagreed with the statement that privately-owned media corporation showed more interest in herbal uses than the government-run media (mean : 2.81 ; mode :2). However, the respondents showed a high level of confidence in the information about health and healthy-living shared through the media (mean : 3.57 ; mode : 4 ), and the frequency of herbal product usage inceases if advertisments are often displayed (mean : $3: 49$; mode : 4). The printed media are also perceived to have played a greater role compared to the electronic media (mean : 3.61 ; mode : 4).

\section{Product commercialisation}

Questions about commercialisation of herbs and herbal products looked at the respondents' views of their potentials and suitability to be commercialised and whether its significance would be wellrecognised by the society, especially by the younger generation. 
Table 1 showed the summaries of the respondents perceptions on herbal products commercialisation. It appeared that the respondents felt and believed that the current industries manufacturing herbal products have the potentials to be expanded and developed (mean:3.89;mode:4) and potential to have a promising future (mean: 4.09;mode:4). Given the chance to invest, respondents were interested in investing for research and development (R\&D) in product commercialisation (mean:3.41;mode:4) compared to developing plantations or manufacturing the product (mean:3.22;mode:3). Respondents nevertheless believed that the mass plantation of the herbs can generate job opportunities for remote communities (mean:4.05;mode:4) with the younger generation giving much notice towards herbs and herbal health products (mean:4.21;mode:4). Respondents also indicated their preferences to buy herbal products (mean:3.59; mode:4), and their positive attitudes concerning its suitability for use in today's current lifestyle (mean:4.04, mode:4).

Table I Summaries on product commercialisation

\begin{tabular}{|c|c|c|c|}
\hline $\begin{array}{l}\text { Potential outcomes for } \\
\text { horticultural activities }\end{array}$ & Mean & Mode & Implications \\
\hline Current Industries & 3.89 & 4 & $\begin{array}{l}\text { Further Expansion } \\
\text { \& Development }\end{array}$ \\
\hline Manufacturing herbal products & 4.09 & 4 & Promising Future \\
\hline \multirow[t]{2}{*}{ Investments (R\&D) } & 3.41 & 4 & $\begin{array}{l}\text { Product } \\
\text { Commercialisation }\end{array}$ \\
\hline & 3.22 & 3 & $\begin{array}{l}\text { Develop } \\
\text { Plantations/ } \\
\text { Production }\end{array}$ \\
\hline $\begin{array}{l}\text { Mass Plantation of Horticultural } \\
\text { Herbs }\end{array}$ & 4.05 & 4 & Job Opportunities \\
\hline Awareness of Product Existence & 4.21 & 4 & $\begin{array}{l}\text { Younger } \\
\text { population }\end{array}$ \\
\hline Sale of Herbal Products & 3.59 & 4 & Highly Prefered \\
\hline $\begin{array}{l}\text { Attitude for Herbal use in } \\
\text { everyday lives }\end{array}$ & 4.05 & 4 & Highly Suitable \\
\hline
\end{tabular}

\section{Discussion}

Descriptive analyses attempted above showed that most of the respondents used herbs daily, albeit in a minimal quantity. The popular usages were in cooking, recording a high percentage of $98.7 \%$ even though some were uncomfortable with herbs perceived as having unpleasant smell and taste. $96.7 \%$ of the respondents use them at home and thought that herbs are a necessity $(92 \%)$. Respondents are found to be aware of the usage of herbs as alternative medicine for certain ailments. This seems to be a common knowledge besides the common use in cooking and culinary servings.

Factors observed were consumers preferences, usage and habits, media endorsement, influential factor, level of consumers' knowledge, and product commercialisation. The respondents supported the statement that the media do play their roles in imparting knowledge on herbs through electronic media, but more so the printed media. Concerning product commercialisation, respondents agreed that herbs should be commercialised at a wider scale due to its perceived benefits. Efforts towards this goal are to be realised by encouraging herbal plantations via agressive horticultural activities, which in turn will generate job opportunities to the local communities. This will come about through planned and guided societal and behaviorial development projects.
Many perceive herbs as one of nature's gifts to mankind and are safe for use. Herbs have also become an accepted part of human life and the current trend is inclined towards better and healthier lifestyles based on the utilisation of natural products including herbs and herbal derivatives or extracts. It is also perceived that the ventures into naturefriendly and natural products including consumables will generate economic benefits attracting further investments, commercialisation and industries exploiting herbs and horticultural activities. Besides being used in medicinal therapies and as food additives, the focussed horticultural herbs have found its niche in product manufacting industries such as herbal soaps and detergents. The findings further implicated that horticultural herbal products do act as alternatives to the chemical-based products available in the market for the growing population of health concious consumers.

\section{Conclusion}

Horticultural herbs as one of nature's gifted plants, are perceived by many that they are safe to be utilised. Treatment at a minimal costs would certainly give an economic motivation for a social and communal development. The current global societal trends are inclined towards a better and healthier lifestyle via herbs and herbal products. Strategies to improve absorption and distribution of these horticultural herbs in foods, and findings from ongoing clinical studies should improve our understanding of how these herbs can best be used to improve human health. Further works to study the impact of consumers' usage on other types of herbs too can help in promoting the discipline of horticulture and exhibits the herbal effect on the everyday lives. It is hoped that ventures into nature-friendly and natural herbal products will ultimately generate economic benefits inclusive of investments, commercialisation and horticultural-herbal based industries.

\section{Funding}

None.

\section{Acknowledgments}

Authors would like to acknowledge Ms Azizah Ibrahim and Ms Hafizah Othman, who had helped in the data collection of study.

\section{Conflicts of interest}

Authors declare no conflict of interest exists.

\section{References}

1. Gilani AH, Rahman AU. Trends in Ethnopharmacology. Journal of Ethnopharmacology. 2005;100(1-2):43-49.

2. Izzo AA, Carlo G Di, Borrelli F, et al. Cardiovascular pharmatherapy, and herbal medicine:the risk of drug interaction. International Journal of Cardioloy. 2005;98 (1):1-14.

3. Samy J, Sugumaran M, Lee KLW, et al. Herbs of Malaysia : an introduction to medicinal, culinary, aromatic and cosmetic use of herb. selangor: Federal Publication Sdn Bhd; 2005.

4. López-Malo A, Barreto-Valdivieso J, Palou E, et al. Aspergillus flavus growth response to cinnamon extract and sodium benzoate mixture. Food Control. 2007;18(11):1358-1362.

5. Wiart C. Medicinal plants of south asia. 2nd edn. Kuala Lumpur: Prentice Hall; 2002.

6. Qin B, Nagasaki M, Ren M, et al. Cinnamon extract (traditional herb) 
potentiates in vivo insulin-regulated glucose utilization via enhancing insulin signaling in rats. Diabetes Research \& Clinical Practice. 2003;62(3):139-148.

7. Qi R, Liao F, Inoue K, Yatomi Y, et al. Inhibition by diallyl trisulfide, garlic component, of intracellular $\mathrm{Ca}(2+)$ mobilization without affecting inositol-1,4, 5-trisphosphate (IP(3)) formation in activated platelets. Biochemical Pharmacology. 2000;60(10):1475-1483.

8. Shukla Y, Kalra N. Cancer chemoprevention with garlic and its constituents Cancer Letters. 2007;247(2):167-181.

9. Rozian Mohd. Sharif. Majalah Rapi, Bil.67. Kuala Lumpur: Karangkraf Sdn. Bhd. 2007.

10. Mansoor GA. Herbs and alternative therapies for hypertension clinic American Journal of Hypertension. 2001;14(9):971-975.

11. Heinerman J. Miracle Healing Herbs. New York : Prentice Hall. 1998.
12. Shukla Y, Singh M. Cancer preventive properties of ginger: a brief review. Food Chemical Toxicology. 2007; 45(5):683-690.

13. Singletary, K. Turmeric: an overview of potential health benefits. food science:nutrition today. September-October. 2010;45 (5):216-225.

14. Fadus MC, Lau C, Bikhchandani J, et al. Curcumin: An age-old antiinflammatory and anti-neoplastic agent. Journal of Traditional and Complementary Medicine. 2017;7(3):339-346.

15.Lopresti AL. The Problem of Curcumin and its bioavailability: could its gastrointestinal influence contribute to its overall health-enhancing effects?. Advances in Nutrition. 2018;9(1):41-50.

16. Wells CS, Wollack JA. An instructor's guide to understanding test reliability. testing and evaluation services, University of Wisconsin, Madison; 2003. 